\title{
A Game-Theoretic Approach to Catching a Cheating Spouse
}

\author{
Amitrajeet A. Batabyal \\ Department of Economics, Rochester Institute of Technology, Rochester, NY, USA \\ Email: aabgsh@rit.edu
}

How to cite this paper: Batabyal, A.A. (2017) A Game-Theoretic Approach to Catching a Cheating Spouse. Theoretical Economics Letters, 7, 464-470.

https://doi.org/10.4236/tel.2017.73035

Received: February 25, 2017

Accepted: April 10, 2017

Published: April 13, 2017

Copyright (C) 2017 by author and Scientific Research Publishing Inc. This work is licensed under the Creative Commons Attribution International License (CC BY 4.0).

http://creativecommons.org/licenses/by/4.0/

\begin{abstract}
In this paper, we study a game model of marital cheating. The husband is the cheater and the wife is faithful. The husband's cheating is either open or surreptitious. The wife can either ignore the cheating or catch her husband in the act of cheating. We first express the game of interest in matrix form. Second, we determine the best response functions of the two players. Third, we show that there exists a unique mixed-strategy Nash equilibrium in the game. Finally, we demonstrate the nexus between our marital cheating game and the prominent Matching Pennies game.
\end{abstract}

\section{Keywords}

Catching, Cheating, Faithful, Mixed-Strategy, Static Game

\section{Introduction}

\subsection{Preliminaries}

In a humorous retort, the now departed American actor and comedian Rodney Dangerfield said "My marriage is on the rocks again, yeah, my wife broke up with her boyfriend." The wit notwithstanding, several writers such as Ali [1], Parker-Pope [2], and Luo et al. [3] have pointed out that with the passage of time, the phenomenon of cheating in a marriage has become more commonplace in the United States.

We can think of the phenomenon of marital cheating as a love for one kind of variety in one's life. Having said this, it is helpful to recall that economists have studied a love for variety and the impact that this love has on consumer welfare in considerable detail at least since the seminal work of Dixit and Stiglitz [4]. In this regard, Fair [5] has contended that a love for variety can also provide a basis for the existence of extramarital affairs or cheating in a marriage and it is this cheating activity that we analyze in the present paper. 
The reader should recognize that the extent of cheating in marriages in the United States is not inconsequential by any means. In addition to the findings discussed by Ali [1], Parker-Pope [2] and Luo et al. [3], research reviewed by Buss and Shackelford [6] demonstrates that between 30 and 60 percent of all married persons in the United States will engage in cheating at some point in their marriages. In spite of the apparent frequency of cheating in marriages, there are very few studies of this phenomenon in the economics literature. As such, we begin by reviewing the extant literature on this subject.

\subsection{Literature Review}

In a dated but nonetheless thoughtful paper, Fair [5] constructs a theoretical model to explain the allocation of an individual's time among spouse, paramour, and work. He then utilizes data from two magazine surveys to test the predictions of his model about the determinants of the time spent with a paramour and finds support for his theoretical model. More recently, Elmslie and Tebaldi [7] have used United States data from the General Social Survey (GSS) to analyze the extent to which demographic and educational variables influence the gender dimension of cheating in marriages. They find that, in general, men and women react dissimilarly to the benefits and costs of having an affair.

Sohn [8] shows that when it is difficult to monitor cheating in a marriage, some people may prefer to stay single rather than be in a partnership because remaining single can be used as a disciplining device to forestall cheating. Potter [9] uses data from the National Youth Survey to reexamine some of the empirical findings in Fair [5]. Specifically and unlike a finding obtained by Fair [5], Potter shows that there is a negative relationship between years of marriage and the phenomenon of cheating in a marriage.

Two empirical findings based on United States data in Adamopoulou [10] are worth noting. First, socioeconomic status is not a factor in determining cheating in a marriage. Second, men and women are equally likely to be unfaithful. Elmslie and Tebaldi [11] use GSS data and show that although the drivers of happiness in a marriage differ between men and women, cheating itself has similar impacts on both the sexes. Finally, Batabyal [12] and Batabyal and Beladi [13] use a static game model to study the optimal effort a wife ought to expend to monitor her potentially cheating husband.

The studies discussed in the preceding three paragraphs have certainly advanced our understanding of cheating in marriages. Even so, two points are now worth stressing. First, the existing studies are mainly empirical and not theoretical in nature. Second, even though the phenomenon of cheating in a marriage has obvious strategic aspects to it, with the exception of Batabyal [12] and Batabyal and Beladi [13], there are no game-theoretic analyses of marital cheating. Our analysis differs from Batabyal [12] and Batabyal and Beladi [13] in two important ways. First, we study a game model in which the husband is not potentially but actually cheating on his wife. Second, the emphasis in our analysis is not on monitoring the potentially cheating spouse but on catching the actually 
cheating spouse ${ }^{1}$. In the course of our analysis, we shall point to the connection between our "catching the cheating spouse" game and the well-known Matching Pennies game.

Given the above delineated lacuna in the literature, in our paper, we analyze a game model of marital cheating. In this model, the wife is faithful and the husband is the cheater. This cheating on the part of the husband is either open or surreptitious. The wife can either disregard the cheating or ensnare her husband in the act of cheating. Section 2.1 first describes the static game-see Gibbons [[15], pp. 1-53] or Tadelis [[16], pp. 43-128] for textbook accounts of static games-that is used to conduct the analysis and then expresses this game in matrix form. Section 2.2 ascertains the best response functions of the two players. Section 2.3 solves for the unique mixed-strategy Nash equilibrium in the game between the cheating husband and the loyal wife. Section 2.4 reveals the connection between our marital cheating game and the well-known Matching Pennies game. Section 3 concludes and then offers two suggestions for extending the research described in this paper.

\section{Analysis}

\subsection{The Game Model}

Consider a man and a woman who are married and live together in the same house. This couple does not have any children and therefore they are the object of each other's love and attention. In what follows, we assume that the wife is faithful to her husband but that the husband is cheating on his wife ${ }^{2}$. The husband (player 2) must choose whether to cheat on his wife openly or to do so surreptitiously. Note that if the husband cheats on his wife openly then it is clear that he really does not care about keeping his marriage intact. As such, the two pure strategies for the husband are denoted by $O$ for cheating openly and $S$ for cheating surreptitiously. The wife (player 1) must decide whether to ignore her husband's cheating or to catch him in the act of cheating. As such, her two pure strategies are denoted by $I$ for ignoring the cheating and $C$ for catching the cheating.

We now need to indicate the payoffs to the husband and to the wife from the pursuit of their two possible pure strategies. The reader should note that these payoffs need to account for the oppositional nature of the strategic relationship in the context of marital cheating. Bearing this point in mind, we suppose that the underlying static game of interest can be delineated in matrix form as follows:

In Table 1, the last two rows in the matrix describe the row player 1's (the wife's) two pure strategies. Similarly, the last two columns in the matrix delineate the column player 2's (the husband's) two pure strategies. Each entry in ${ }^{1}$ See Greenberg et al. [14] for a different theoretical standpoint.

${ }^{2}$ There would be no noteworthy change in our analysis if the husband is assumed to be faithful and the wife the cheater. Hence, this assumption is without loss of generality. Having said this, the reader should understand that if both spouses potentially cheat on each other then the analysis in this paper will need to be modified. 
Table 1. The marital cheating game in matrix form.

\begin{tabular}{lccc}
\hline & \multicolumn{3}{c}{ Husband (Player 2) } \\
\hline Wife (Player 1) & & Cheat Openly $(O)$ & Cheat Surreptitiously $(S)$ \\
\hline & Catch Cheating $(C)$ & $20,-10$ & 0,0 \\
& Ignore Cheating $(I)$ & 10,10 & 10,0 \\
\hline
\end{tabular}

the matrix consists of a pair of numbers. The first number refers to the row player's payoff and the second number denotes the column player's payoff. With this background in place, our next task is to ascertain the best response functions of the two players.

\subsection{Best Response Functions}

Let $u_{1}(\cdot, \cdot)$ and $u_{2}(\cdot, \cdot)$ denote the payoff functions of the wife (player 1$)$ and the husband (player 2). In addition, let $p \geq 0$ denote the probability that the wife selects $C$ and therefore $(1-p) \geq 0$ denotes the probability that she selects $I$. Similarly, let $q \geq 0$ denote the probability that the husband chooses $O$ and hence $(1-q) \geq 0$ denotes the probability that he chooses $S$.

The structure of the individual payoffs in the game depicted in Table 1 and some thought together tell us that the wife will attempt to catch her husband cheating on her (play $C$ ) and not ignore his cheating (play $I$ ) if and only if her payoff from catching her husband cheating exceeds her payoff from ignoring his cheating. This means that mathematically, we must have

$$
u_{1}(C, q)>u_{1}(I, q) \Leftrightarrow 20 q>10 \Leftrightarrow q>1 / 2 .
$$

Utilizing the logic leading to (1), it should be clear to the reader that the wife will prefer to ignore her husband's cheating and not attempt to catch him as long as $q<1 / 2$. Finally, when the probability $q=1 / 2$, the wife is indifferent between attempting to catch her husband cheating and ignoring this cheating.

Let us now focus on the incentives confronting the husband. It is straightforward to confirm that instead of cheating on his wife surreptitiously (playing $S$ ), the husband will prefer to cheat on her openly (play $O$ ) if and only if his payoff from cheating openly exceeds his payoff from cheating surreptitiously. Mathematically, this means that we must have

$$
u_{2}(p, O)>u_{2}(p, S) \Leftrightarrow-10 p+10(1-p)>0 \Leftrightarrow p<1 / 2 .
$$

The inequalities in (2) tell us that the husband will prefer to cheat on his wife surreptitiously when the probability $p>1 / 2$ and that he will be indifferent between cheating openly and surreptitiously when this same probability $p=1 / 2$.

Using the analysis in the previous two paragraphs, we can express the best response functions of the wife and the husband. To this end, let $B_{1}^{*}(q)$ and $B_{2}^{*}(p)$ denote the wife's and the husband's best response functions. Then, using our analysis thus far, we get

$$
B_{1}^{*}(q)=\left\{\begin{array}{ll}
p=0 & \text { if } q<1 / 2 \\
p \in[0,1] & \text { if } q=1 / 2 \\
p=1 & \text { if } q>1 / 2
\end{array}\right\} .
$$


And

$$
B_{2}^{*}(p)=\left\{\begin{array}{ll}
q=1 & \text { if } p<1 / 2 \\
q \in[0,1] & \text { if } p=1 / 2 \\
q=0 & \text { if } p>1 / 2
\end{array}\right\}
$$

Our next task is to solve for the unique mixed-strategy Nash equilibrium in the game between the cheating husband and the loyal wife.

\subsection{Mixed-Strategy Nash Equilibrium}

As a prelude to solving for the mixed-strategy Nash equilibrium, we would first like to point out that there is no pure-strategy Nash equilibrium in the marital cheating game that we have been studying thus far. To see this clearly, let us revisit Table 1 . We see that when the wife plays pure strategy $C$ it is optimal for her husband to play $S$. Similarly, when the wife plays pure strategy $I$ it is optimal for the same husband to play $O$. Looked at from the viewpoint of the husband, when he plays $O(S)$ it is optimal for his wife to play $C(I)$. In other words, in the game described in Table 1, we have a scenario in which one player would like to match the action of the other player (if the husband cheats openly then the wife would like to catch him cheating) but the other player would like to circumvent this matching (if the wife tries to catch the husband cheating then the husband would prefer to cheat surreptitiously).

Now, moving on to the unique mixed-strategy Nash equilibrium, observe from Equation (3) and our analysis thus far that the wife (player 1) will be willing to mix between her two pure strategies $C$ and $I$ if and only if $u_{1}(C, q)=$ $u_{1}(I, q)$ and this equality holds only when the probability $q=1 / 2$ Similarly, equation (4) and some thought tell us that the husband (player 2) will be willing to mix between his two pure strategies $O$ and $S$ if and only if $u_{2}(O, p)=u_{2}(S, p)$. This last condition holds only when the probability $p=1 / 2$. Collecting this information about the two probabilities $p$ and $q$, we deduce that the unique mixed-strategy Nash equilibrium of our game is where $(p, q)=$ $(1 / 2,1 / 2)$. Put differently, in the game under study, the husband cheats on his wife openly with probability $q=1 / 2$ and the wife catches him cheating openly with probability $p=1 / 2$. Our final task in this paper is to establish the relationship between our marital cheating game and the well-known Matching Pennies game.

\subsection{Nexus with the Matching Pennies Game}

In the Matching Pennies game, players 1 and 2 each place a penny on a table concurrently. If the resulting outcome is two heads or two tails then player 1 gets to keep both the pennies. If this is not the resulting outcome then player 2 keeps the two pennies. This game is well known and is standardly discussed in game theory textbooks such as Gibbons [[15], pp. 29-33] and Tadelis [[16], pp. 108$111]$.

The reader should note that the incentives facing the husband and the wife in our marital cheating game and the incentives confronting the two players in the 
Matching Pennies game are very closely linked. In this regard, consistent with the discussion in section 2.3, note that in both games being compared, we have a scenario in which one player wants to match the action of the other player but the other player wants to get around this matching. As noted previously, this is also why a pure-strategy Nash equilibrium does not exist in both these games and the only Nash equilibrium is in mixed-strategies. This completes our gametheoretic perspective on catching a cheating spouse.

\section{Conclusion}

In this paper, we analyzed a game model of marital cheating. Our analysis did not focus on the phenomenon of divorce in a marital relationship and nor did it address the fact that the interaction between the husband and the wife in a marriage typically occurs repeatedly over time. Therefore, it would be useful to analyze how the possibility of divorce affects the cheating behavior of the husband or, more generally, either spouse in a marital relationship. Second, it would also be interesting to study how the incentives confronting the husband and the wife in the "cheating and catching" static game analyzed in this paper change when the underlying game is repeated over time. Game-theoretic studies of marital cheating that incorporate these features of the problem into the analysis will provide additional insights into a phenomenon that has significant economic and societal implications for a non-negligible proportion of society.

\section{Acknowledgements}

Batabyal thanks two anonymous reviewers for their helpful comments on a previous version of this paper and Cassandra Shellman for her help in formatting the final version of the paper. In addition, he acknowledges financial support from the Gosnell endowment at RIT. The usual disclaimer applies.

\section{References}

[1] Ali, L. (2004) Marriage: The New Infidelity. Newsweek, August 8.

[2] Parker-Pope, T. (2008) Love, Sex, and the Changing Landscape of Infidelity. New York Times, October 27.

[3] Luo, S., Cartun, M.A. and Snider, A.G. (2010) Assessing Extradyadic Behavior: A Review, a New Measure, and Two New Models. Personality and Individual Differences, 49, 155-163.

[4] Dixit, A.K. and Stiglitz, J.E. (1977) Monopolistic Competition and Optimum Product Diversity. American Economic Review, 67, 297-308.

[5] Fair, R.C. (1978) A Theory of Extramarital Affairs. Journal of Political Economy, 86, 45-61.

[6] Buss, D.M. and Shackelford, T.K. (1997) Susceptibility to Infidelity in the First Year of Marriage. Journal of Research in Personality, 31, 193-221.

[7] Elmslie, B. and Tebaldi, E. (2008) So What Did You Do Last Night? The Economics of Infidelity. Kyklos, 61, 391-410.

[8] Sohn, K. (2008) Why Are There Singles: Being Single in Equilibrium as a Partner Discipline Device. Economics Bulletin, 10, 1-6. 
[9] Potter, J. (2011) Reexamining the Economics of Marital Infidelity. Economics Bulletin, 31, 41-52.

[10] Adamopoulou, E. (2013) New Facts on Infidelity. Economics Letters, 121, 458-462.

[11] Elmslie, B. and Tebaldi, E. (2014) The Determinants of Marital Happiness. Applied Economics, 46, 3452-3462.

[12] Batabyal, A.A. (2017) Marital Infidelity: A Game-Theoretic Analysis. RIT Economics Department Working Paper No. 17-4.

[13] Batabyal, A.A. and Beladi, H. (2017) Cheating on Your Spouse: A Game-Theoretic Analysis. Theoretical Economics Letters, 7, 79-85.

[14] Greenberg, J., Luo, X., Oladi, R. and Shitovitz, B. (2002) (Sophisticated) Stable Sets in Exchange Economies. Games and Economic Behavior, 39, 54-70.

[15] Gibbons, R. (1992) A Primer in Game Theory. Harvester Wheatsheaf, Hemel Hempstead.

[16] Tadelis, S. (2013) Game Theory. Princeton University Press, Princeton.

Submit or recommend next manuscript to SCIRP and we will provide best service for you:

Accepting pre-submission inquiries through Email, Facebook, LinkedIn, Twitter, etc. A wide selection of journals (inclusive of 9 subjects, more than 200 journals) Providing 24-hour high-quality service User-friendly online submission system Fair and swift peer-review system Efficient typesetting and proofreading procedure Display of the result of downloads and visits, as well as the number of cited articles Maximum dissemination of your research work

Submit your manuscript at: http://papersubmission.scirp.org/ Or contact tel@scirp.org 